Review began 08/29/2021 Review ended 09/07/2021 Published 09/10/2021

๑) Copyright 2021

Khurana et al. This is an open access article distributed under the terms of the Creative Commons Attribution License CCBY 4.0., which permits unrestricted use distribution, and reproduction in any medium, provided the original author and source are credited.

\section{A Potentially Dangerous Industrial Projectile Lodged in the Leg of a Steel Factory Worker}

\author{
Ankit Khurana ${ }^{1}$, Vishal Jain ${ }^{1}$, Shailendra C. Gupta ${ }^{1}$, Kuldeep Malik ${ }^{1}$, Sudhir Gupta ${ }^{2}$ \\ 1. Orthopaedics, ESI Hospital Rohini, Delhi, IND 2. Anaesthesiology, ESI Hospital Rohini, Delhi, IND \\ Corresponding author: Ankit Khurana, ankit24388@gmail.com
}

\begin{abstract}
Penetrating injuries due to fragments energized by an explosive event are life/limb-threatening and are associated with poor clinical and functional outcomes. Penetrating injuries are commonly inflicted in attacks with explosive devices. The extremities, especially the leg, are the most commonly affected body areas, presenting a high risk of infection, slow recovery, and the threat of amputation. This report presents a case of a young factory worker who sustained an injury to the leg with a foreign body lodged near the neurovascular bundle.

A 44-year-old gentleman sustained a projectile injury while working in a stainless steel factory from the rula (steel rolling) machine with a foreign body getting lodged in the leg in March 2019. He was initially managed with wound care and didn't report any functional impairment. Gradually patient developed numbness and claudication symptoms of the foot over the next couple of years. He was subsequently operated on in 2021 for removal of the stainless steel foreign body encased in dystrophic calcification close to the tibial nerve and posterior tibial vessels. Interestingly the entry point of the foreign body was on the anterolateral aspect of the leg. The foreign body was removed using the postero-lateral approach to the tibia with careful dissection close to the neurovascular bundle. At a follow-up of 3 months, the patient is symptom-free with significant improvement of limb function.
\end{abstract}

The authors propose that the foreign body crossed the interosseous membrane to get lodged close to the posterior tibial neurovascular bundle. In such a scenario, the patient was extremely lucky to have survived an amputation or significant functional injury of the limb. Proper protective equipment is needed not only for the torso but also for extremities to protect industrial workers from such limb-threatening injuries. Moreover, primary care physicians should be sensitised for the proper management of such injuries.

Categories: Preventive Medicine, Orthopedics

Keywords: dystrophic calcification, injury biomechanics, foreign body, factory injury, employment injury

\section{Introduction}

Energized fragment penetration is a common injury modality among blast injuries in factories. Penetrating injuries due to fragments energized by an explosive event can be life as well as limb-threatening [1]. These are often associated with poor clinical and functional outcomes due to the significant kinetic energy of these projectiles [2]. There is a wide range of factors that can potentially affect injury outcomes, such as impact velocity, projectile mass, and shape [3-5]. The majority of such ballistics research currently focuses on gunshot wounds, and limited objective experimental evidence exists to quantify the potential injurious mechanisms of energized fragments from factory equipment.

This report brings to light one such interesting and potentially limb-threatening injury to the leg of a young factory worker employed in a semi-urban steel factory in India who sustained a projectile injury to the leg with a foreign body lodged near the neurovascular bundle that over time caused claudication symptoms.

\section{Case Presentation}

A 44-year-old gentleman sustained a projectile injury to the leg in March 2019 while working in a stainless steel factory from a rula (steel rolling) machine. He was initially managed with wound care by a local practitioner and didn't report any functional impairment. No radiological investigation was performed at this time. Gradually over the next two years, the patient began developing numbness and claudication symptoms of the foot which worsened over time. The patient presented to the authors in January 2021 when the first radiographs were performed, which revealed a foreign body lodged in the leg (Figure 1). 


\section{Cureus}

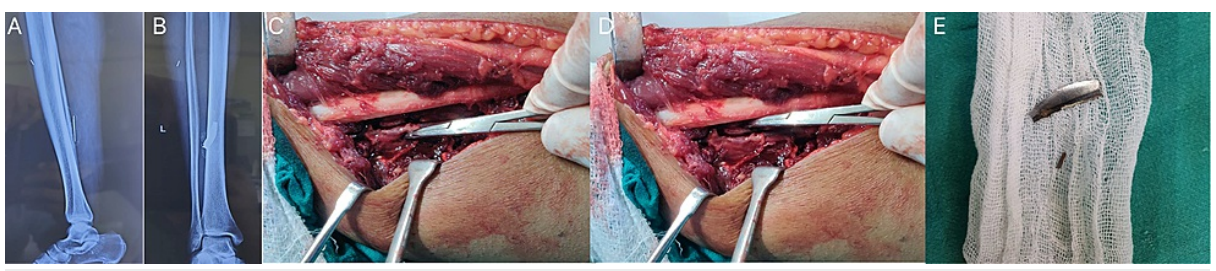

FIGURE 1: Radiographs, preoperative images, and extracted foreign body

A 44-year-old male with a metal foreign body present in the posterolateral aspect of the tibia depicted radiographically $(1 \mathrm{~A}$ and $\mathrm{B})$. Preoperative images $(1 \mathrm{C}$ and $\mathrm{D})$ using the posterolateral approach show close proximity of the foreign body (marked by haemostat in 1D) to the posterior tibial vessels as pointed by haemostat in figure $1 \mathrm{C}$. Following extraction, the foreign body is seen to be a sharp steel projectile of size $3 \times 1 \mathrm{~cm}$ (1E)

He was subsequently operated and a posterolateral approach was chosen to extract the foreign body. A $10 \mathrm{~cm}$ longitudinal incision was taken over the lateral border of the gastrocnemius muscle centred over the radiographic location of the foreign body. The internervous plane which lies between the gastrocnemius, soleus, and flexor hallucis longus muscles (tibial nerve) and the peroneal muscles (superficial peroneal nerve) was used taking care not to injure the short saphenous vein and peroneal artery.

The stainless steel foreign body was found encased in dystrophic calcification in close proximity to the tibial nerve and posterior tibial vessels (Figure 1). The foreign body was subsequently removed using careful dissection close to the neuro-vascular bundle and was found to be sharp stainless steel shrapnel of size $3 \times 1 \mathrm{~cm}$ (Figure 1). Interestingly, the entry point of the foreign body was on the anterolateral aspect of the leg. At a follow-up of 3 months, the patient was symptom-free with significant improvement of limb function.

\section{Discussion}

Based on our literature search, this study is the first to evaluate injury due to penetration of steel factory projectile to the musculoskeletal system. Foreign bodies such as bullets, shotgun pellets, and shrapnel can cause clinical symptoms by mechanical compression [6], lumen obstruction [7], irritation of nearby structures [8], systemic heavy metal intoxication [9], or tumour formation [10,11]. Chong et al. have proposed the use of particle-based computational methods to simulate injury and haemorrhage in the human body, and their study demonstrates a significant haemorrhage following a ballistic injury to the leg [12].

Similar to our findings, an ischemic syndrome has been demonstrated in a 5-year-old girl with a gun-shot wound to the shoulder with an arterial embolus at the elbow leading to ischaemic symptoms [13]. There have also been reports of cardiac embolisation of metallic foreign bodies which are perivascular and have been retrieved by the trans-femoral route [14]. A similar report presents a pulmonary embolization of one such metallic foreign body, further emphasizing the dangerous nature of peri-vascular foreign bodies [15].

Additionally, projectile foreign bodies are known to cause chronic heavy metal toxicity due to the release of metal into the bloodstream [16]. Usually, metallic objects embedded into the soft tissue become encapsulated and do not release metals into the systemic circulation. However, there are exceptions to this rule [8]. Missiles close to the bone, [17], joints, and intervertebral disks are continuously bathed with synovial fluid, which eventually washes off lead from the bullets resulting in systemic toxicity $[18,19]$. Females are more vulnerable to this form of toxicity which can then lead to neuropathy [16,20].

The authors propose that the projectile narrowly missed the anterior tibial neurovascular structures, including the deep peroneal nerve and anterior tibial artery and vein and crossed the interosseous membrane to lodge in close proximity to the posterior tibial artery and tibial nerve (Figure 2). The foreign body pressed on these structures to cause claudication like features. As the patient didn't have an infection of the wound or a significant loss of significant function, he ignored the claudication symptoms, which gradually increased over the next two years. With time, as the symptoms grew, the patient reported to us. Following removal, the patient noticed an immediate relief of symptoms, further proving the cause of claudication as the foreign body. 


\section{Cureus}

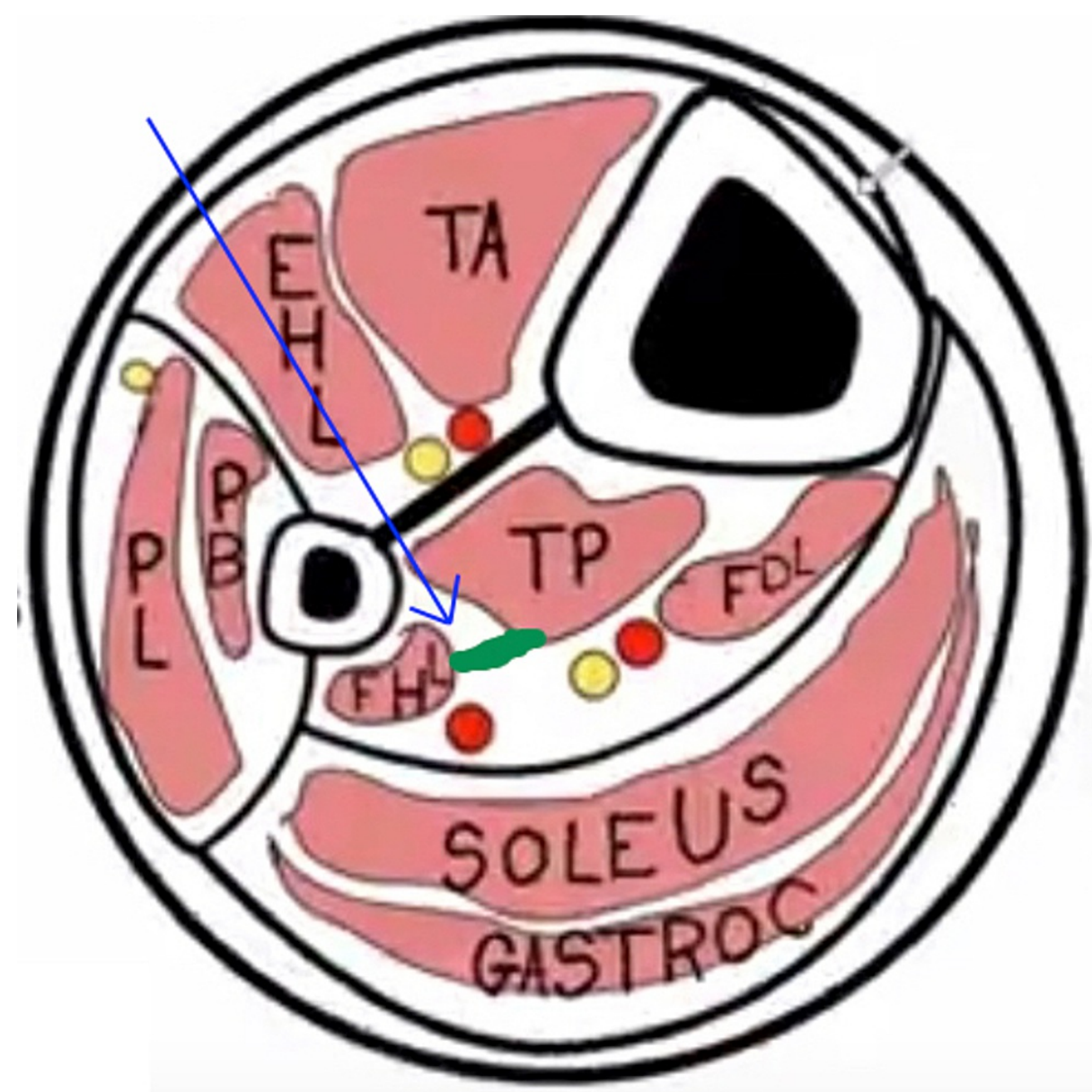

FIGURE 2: Diagram of the proposed trajectory of the projectile

Showing the proposed trajectory of the projectile (blue arrow) and the foreign body (depicted in green) getting lodged in close proximity to the posterior tibial vessels and tibial nerve.

\section{Conclusions}

Keeping the above-mentioned risks in mind, proper protective equipment is needed not only for the torso but also for extremities to protect industrial workers from such limb-threatening injuries. Primary care physicians should be sensitised to these industrial injuries so that they can be properly evaluated and managed in primary care settings. Our findings can be used to predict the dangers due to industrial projectile trauma, instigating the development of situation-appropriate personal protective equipment as well as initiate implementation of mitigating strategies to avoid such mishaps in the future.

\section{Additional Information}

\section{Disclosures}

Human subjects: Consent was obtained or waived by all participants in this study. Conflicts of interest: In compliance with the ICMJE uniform disclosure form, all authors declare the following: Payment/services info: All authors have declared that no financial support was received from any organization for the submitted work. Financial relationships: All authors have declared that they have no financial relationships at present or within the previous three years with any organizations that might have an interest in the submitted work. Other relationships: All authors have declared that there are no other relationships or activities that could appear to have influenced the submitted work.

\section{Acknowledgements}

We would like to acknowledge Dr Ankita Sethi, Department of Obstetrics and Gynaecology, AIIMS, New Delhi, for support and guidance.

\section{References}

1. Mittal C, Vempalli SR, Kanchan T, Shekhawat RS: Fatal penetrating abdominal injury by a metallic 
projectile. J Forensic Sci. 2021, 10.1111/1556-4029.14828

2. Jaiswal A, Habib M, Tanwar Y-S: Neglected foreign body in contralateral limb in a traumatic transfemoral amputee-radiographs can be misleading. Chin J Traumatol. 2013, 16:61-4. 10.3760/cma.j.issn.10081275.2013.01.013

3. Santucci RA, Chang YJ: Ballistics for physicians: myths about wound ballistics and gunshot injuries. J Urol. 2004, 171:1408-14. 10.1097/01.ju.0000103691.68995.04

4. Hollerman JJ, Fackler ML, Coldwell DM, Ben-Menachem Y: Gunshot wounds: 1. bullets, ballistics, and mechanisms of injury. AJR Am J Roentgenol. 1990, 155:685-90. 10.2214/ajr.155.4.2119095

5. Woodcock MG, Scott RA, Huntbach J, Kirkby GR: Mass and shape as factors in intraocular foreign body injuries. Ophthalmology. 2006, 113:2262-9. 10.1016/j.ophtha.2006.06.002

6. Link MJ, Driscoll CL, Esquenazi Y: Vagoglossopharyngeal-associated syncope due to a retained bullet in the jugular foramen. Skull Base. 2010, 20:105-9. 10.1055/s-0029-1225532

7. Mincheff TV: Bullet fragment within the appendix: a case report . J S C Med Assoc. 2004, 100:270-3.

8. Eylon S, Mosheiff R, Liebergall M, Wolf E, Brocke L, Peyser A: Delayed reaction to shrapnel retained in soft tissue. Injury. 2005, 36:275-81. 10.1016/j.injury.2004.09.005

9. Linden MA, Manton WI, Stewart RM, Thal ER, Feit H: Lead poisoning from retained bullets. Pathogenesis, diagnosis, and management. Ann Surg. 1982, 195:305-13. 10.1097/00000658-198203000-00010

10. Keel SB, Jaffe KA, Petur Nielsen G, Rosenberg AE: Orthopaedic implant-related sarcoma: a study of twelve cases. Mod Pathol. 2001, 14:969-77. 10.1038/modpathol.3880420

11. Schmitt HP: [Trauma and tumor: malignant glioma in the area of a traumatic lesion of the brain with metal scales]. Fortschr Neurol Psychiatr. 1983, 51:227-31. 10.1055/s-2007-1002228

12. Chong K, Jiang C, Ram D, et al.: Visualization of vascular injuries in extremity trauma. Med Biol Eng Comput. 2017, 55:1709-18. 10.1007/s11517-017-1619-9

13. Schoofs M, Bovet JL, Baudet J: [Embolization of the brachial artery by lead-shot with ischemic syndrome] . J Chir (Paris). 1983, 120:271-3.

14. Best IM: Transfemoral extraction of an intracardiac bullet embolus . Am Surg. 2001, 67:361-3.

15. Dulić G, Candrlić K, Blazeković R, Sego K, Gasparović H, Sarić G, Candrlić-Kalajdzić J: Pulmonary embolism caused by a migrated gunshot projectile. Coll Antropol. 2007, 31:629-31.

16. Bilen B, Ates Alkan F, Barutcu UB, Sezen M, Unlu MB, Aghayev K: Examination of metal mobilization from a gunshot by scanning acoustic microscopy, scanning electron microscopy, energy-dispersive X-ray spectroscopy, and inductively coupled plasma optical emission spectroscopy: a case report. J Med Case Rep. 2018, 12:391. 10.1186/s13256-018-1905-7

17. McQuirter JL, Rothenberg SJ, Dinkins GA, Manalo M, Kondrashov V, Todd AC: The effects of retained lead bullets on body lead burden. J Trauma. 2001, 50:892-9. 10.1097/00005373-200105000-00020

18. Slavin RE, Swedo J, Cartwright J, Viegas S, Custer EM: Lead arthritis and lead poisoning following bullet wounds: a clinicopathologic, ultrastructural, and microanalytic study of two cases. Hum Pathol. 1988, 19:223-35. 10.1016/S0046-8177(88)80353-8

19. Gameiro VS, de Araújo GC, Bruno FM: Lead intoxication and knee osteoarthritis after a gunshot: long-term follow-up case report. BMJ Case Rep. 2013, 2013: 10.1136/bcr-2013-009404

20. Porter S, Hanley E, Sing RF: Fetal anomalies resulting from maternal bullet-related plumbism. J Trauma. 2004, 56:1353-5. 10.1097/01.ta.0000063020.84255.8e 